Kansas State University Libraries

New Prairie Press

\title{
MIXED MODELS COMBINED ANALYSIS OF INDEPENDENT GRAZING TRIALS
}

\author{
H. A. Fribourg \\ J. C. Waller \\ R. W. Thompson \\ W. L. Sanders
}

See next page for additional authors

Follow this and additional works at: https://newprairiepress.org/agstatconference

Part of the Agriculture Commons, and the Applied Statistics Commons

\section{(c) (1) $\Theta$}

This work is licensed under a Creative Commons Attribution-Noncommercial-No Derivative Works 4.0 License.

\section{Recommended Citation}

Fribourg, H. A.; Waller, J. C.; Thompson, R. W.; and Sanders, W. L. (1993). "MIXED MODELS COMBINED ANALYSIS OF INDEPENDENT GRAZING TRIALS," Conference on Applied Statistics in Agriculture. https://doi.org/10.4148/2475-7772.1374

This is brought to you for free and open access by the Conferences at New Prairie Press. It has been accepted for inclusion in Conference on Applied Statistics in Agriculture by an authorized administrator of New Prairie Press. For more information, please contact cads@k-state.edu. 


\section{Author Information}

H. A. Fribourg, J. C. Waller, R. W. Thompson, and W. L. Sanders

This is available at New Prairie Press: https://newprairiepress.org/agstatconference/1993/proceedings/8 


\title{
MIXED MODELS COMBINED ANALYSIS OF INDEPENDENT GRAZING TRIALS
}

\author{
H. A. Fribourg, J. C. Waller, R. W. Thompson, and W. L. Sanders \\ University of Tennessee
}

\begin{abstract}
The mixed models procedure (MMP) was used to analyze pooled data sets from 12 independent studies over $13 \mathrm{yr}$ at 9 locations in 7 states to provide combined estimates of daily gains by beef steers grazing tall fescue pastures with different levels of infestation by Acremonium coenophialum, with and without clover. Spring, summer, and combined spring + summer data were analyzed separately. The MMP permitted estimation of the fixed effects of treatments over a broad inference space of future years and different tall fescue pastures over a wide geographic range, detected some relationships not apparent in the individual studies, and provided a more coherent body of information than do the results obtained from each discrete study. Logistical and financial constraints that force undesirable compromises in the conduct of future grazing and other expensive or time-consuming research may be avoided by using MMP within the context of cooperative projects.
\end{abstract}

Keywords: Mixed models, Combined analysis, Grazing trials

\section{INTRODUCTION}

Recent identification of the extensive tall fescue toxicosis problem in the eastern United States led to the initiation during the 1980s of several independent trials that examined similar treatments using comparable livestock and grazing methodologies at different locations. The consequent existence of a substantial body of relatively comparable data provided a unique opportunity for a combined analysis.

There have been few attempts to combine either raw data or final results from independent, but similar, grazing trials (Hedges and Olkin, 1985; Petersen and Lucas, 1960). In grazing research, only a few treatments can be explored in any one trial. Few separate trials have addressed the same questions. Grazing research is expensive and unwieldy because it requires several years of data which are usually associated with large

- variances. Since many grazing trials have a small number of degrees of freedom for error, they often have insufficient power for detecting small differences among treatments. As progress is made in forage/livestock systems, investigators look for smaller effects, typically without the budgetary increases required for more sensitive trials.

Combined analyses of large sets of data are now possible, with the advent of sufficiently large and usable computing power, and the gradual acceptance and understanding of mixed model methods. Combining data from independent trials may help uncover patterns of underlying relations, facilitate analysis of multi-location research, and lead to more sensitive evaluation and improved efficiency of research 
resource utilization. Another powerful advantage of the technique is the ability to compare treatment combinations that do not exist at any location, even though elements of these combinations occur at other locations in a multi-location analysis; this is analogous to comparing treatments in an incomplete block design.

The mixed models procedure (Henderson, 1975) provides an orderly process in which to view several seemingly disjointed experiments as part of a bigger whole. In the application presented here, it makes it possible to estimate steer performance over a broad inference space of future years and different pastures of similar botanical composition and management (McLean et al., 1991) from data obtained in a number of independent studies which had some identical experimental protocols for at least two treatments in at least one of the possible groupings of two or more locations.

This report will illustrate the use of the mixed models procedure to provide combined estimates of average daily gain (ADG) of steers grazing tall fescue pastures with different levels of infestation by the fungal endophyte Acremonium coenophialum, with and without clover, obtained from a number of independent grazing trials where similar treatments using similar protocols were used to study the tall fescue toxicosis problem.

\section{Biological Nature of the Problem}

Detrimental effects on steer performance resulting from consumption of tall fescue pastures infested with the endophytic fungus Acremonium coenophialum have been documented widely since the fungus was first implicated in tall fescue toxicosis (Stuedemann and Hoveland, 1988). This problem is serious in the transition zone (southern Illinois and Ohio south to northern Mississippi and Georgia, eastern Oklahoma east to the Piedmont in Virginia and the Carolinas) of the United States, affecting more than 15 million hectares (Figure 1). Annual economic losses are estimated to be over $\$ 600$ million for beef cattle alone (Hoveland, 1993). Several investigations have shown that inclusion of legumes into sods of endophyte-infected $(E+)$ plants or the use of endophyte-free (E-) cultivars has improved animal performance (Fribourg et al., 1991). Endophyte-free tall fescue may be less persistent and pest resistant than is E+ tall fescue (Bacon and Siegel, 1988).

Most information concerning effects of this fungal endophyte on livestock performance was obtained from grazing trials conducted as discrete endeavors. Differences in soils, agronomic practices, animal genotypes or management, climatic situations or seasons of the year, and other environmental conditions, have warranted the repetition of similar treatments in tall fescue research throughout the transition zone. Conversely, results obtained at a single location during one year or for two or more consecutive years, however accurate themselves, are of limited value, either for the immediately practical end of determining the most profitable forage combinations, stocking rates, level of fertilization, and so on, or for the scientifically desirable goal of establishing associations or relationships. A combined analysis should be useful for characterizing and predicting steer performance and its variability over the range of tall fescue adaptation in the eastern United States. 


\section{MATERIALS AND METHODS}

Data sets were pooled from 12 independent tall fescue grazing trials conducted during 1979 to 1991 at Marion Junction, AL; Hope, AR; Calhoun, GA; Simpson, IL; Mount Vernon, MO; Grand Junction, Greeneville, and Knoxville, TN; and Middleburg, VA (Figure 1). Thirty-seven location-years of data were combined for the spring season analysis. For the summer season and the combined spring + summer analyses, data sets were pooled from the five trials conducted at the three Tennessee locations and at Calhoun, GA, for a total of 17 location-years.

All data set contributors provided, from published reports and supplementary personal communications, complete summaries of the experimental methodologies, description of pertinent biological and environmental variables, experimental design used including number and sizes of pastures, and so on, for their respective experiments (Thompson $e t$ al., 1993). In each of the five trials conducted in Tennessee, treatments were arranged in randomized complete block designs with two replications. In the other states, treatments were arranged in completely random or incomplete block designs with at least two pastures per treatment. Each experiment, regardless of location, included at least two, but not more than four, of the six treatments included in the combined analysis. Steers included the commonly used beef genotypes for each research location, hence the effect of animal genotype was confounded with the location effect.

Tall fescue treatments used in the combined analyses were grouped into lowendophyte (LE: $\leq 5 \% \mathrm{E}+$ ), moderately infested (ME: $\geq 20$ to $\leq 35 \% \mathrm{E}+$ ), and highly infested (HE: $\geq 50$ to $\leq 97 \% \mathrm{E}+$ ) tall fescue and, in tall fescue-clover mixtures (with about 20 to $40 \%$ clover in spring, and about $10 \%$ in summer), low endophyte (LECL), moderately infested (MECL), and highly infested (HECL) tall fescue at the same E+ ranges. Forage treatments other than those involving tall fescue, with and without clover, were not used in the combined analyses.

The combined evaluations were made using the method described originally by Henderson (1975) and more recently by McLean et al. (1991) as implemented in the General Linear Mixed Models (GLMM) software (Blouin and Saxton, 1990). The mixed model used for the analysis of the combined grazing trials was as follows:

$$
\begin{aligned}
& \mathrm{G}_{\mathrm{ijklm}}=\mathrm{b}_{0}+\mathrm{b}_{1} \mathrm{IW}_{\mathrm{ijklm}}+\mathrm{b}_{2} \mathrm{GD}_{\mathrm{ijklm}}+\mathrm{L}_{\mathrm{i}}+\mathrm{Y}_{\mathrm{j}: \mathrm{i}}+\mathrm{T}_{\mathrm{k}}+\mathrm{LT}_{\mathrm{ik}}+\mathrm{YT}_{\mathrm{j} k \mathrm{i}}+\mathrm{R}_{\mathrm{jlli}}+\epsilon_{\mathrm{j} \mathrm{k} k \mathrm{~m}}, \\
& \text { where } \quad \mathrm{G}_{\mathrm{ijklm}}=\text { spring } \mathrm{ADG} \text { (grams/day), } \\
& \mathrm{b}_{0}=\text { intercept, } \\
& \mathrm{b}_{1} \mathrm{IW}_{\mathrm{ijklm}}=\text { initial weight (kilograms) covariate, } \\
& \mathrm{b}_{2} \mathrm{GD}_{\mathrm{ijklm}}=\text { steer grazing days/hectare covariate, } \\
& \mathrm{L}_{\mathrm{i}}=\text { locations, } \\
& \mathrm{Y}_{\mathrm{j}: \mathrm{i}}=\text { years within locations, } \\
& \mathrm{T}_{\mathrm{k}}=\text { treatments, } \\
& \mathrm{LT}_{\mathrm{ik}}=\text { locations } \mathrm{x} \text { treatments, } \\
& \mathrm{TY}_{\mathrm{jk}: \mathrm{i}}=\text { treatments } \mathrm{x} \text { years within locations, }
\end{aligned}
$$




$$
\begin{aligned}
& \mathrm{R}_{\mathrm{jl}: \mathrm{i}}=\text { (blocks } \mathrm{x} \text { years) within locations, and } \\
& \epsilon_{\mathrm{ijklm}}=\text { residual error on a pasture basis. }
\end{aligned}
$$

To estimate mean steer ADG for each treatment across all locations, all classification effects were defined as random except for the main effect of treatments. The assumption that locations were random samples of the tall fescue pasture population in the eastern United States is defensible. Tall fescue is widespread and well adapted within a large zone in the eastern United States (Figure 1) and the study locations were disseminated throughout this adaptation range. The experimental locations shown on the map were not originally selected because of any intrinsic characteristic performance of either tall fescue or beef cattle, but rather for other unrelated reasons. Therefore, for the purpose of this study, it seems appropriate to consider locations as random effects. Years were nested within locations because the climatic situations at one location were judged not to be representative of those at other locations; temperature and precipitation effects were confounded within the year and location effects. Blocks were identified uniquely in the randomized complete block designs, and a value of 1 was assigned to blocks in the completely random designs.

For each season, restricted maximum likelihood estimates of variance (REML) components corresponding to the random effects were obtained after removing the variation resulting from the continuous covariates and adjusting for all fixed effects. Seasonal generalized least squares ADG means and SE, and estimated differences of five pre-planned linear contrasts of greatest interest from among the many possible contrasts within a six-treatment structure, and their SE, were predicted.

To determine whether the residual variances among locations were homogeneous, the random residual variances were estimated separately for each year within each location, and these were tested for each grazing season using Bartlett's test of homogeneity. The separate seasonal tests of homogeneity indicated that the residual variances were homogeneous ( $\mathrm{P}>.05$ ), allowing us to pool the $\mathbf{G}$ and $\mathbf{R}$ variances in the combined analyses.

Inference space is the set of elements, or population, to which a predictable function (PF) is intended to apply, as defined by Stroup (1989b). A PF is a carefully chosen linear combination of the solution vector, and is the mixed model generalization of estimable functions. A narrow PF confines inferences to only the specific realized values of the random variables in the experiment, as used by Harville (1985), and a broad PF makes inferences over all possible levels of the random variables. Three predictable functions were defined to obtain treatment ADG means, depending on the implied inference spaces and utilizing the procedures outlined in McLean et al. (1991). The narrow PF allows inferences about average treatment ADG in the specific pastures at the listed locations during the years when grazing was conducted. At the other extreme, the broad PF estimates mean steer ADG for each treatment in future years and different pastures of similar characteristics within the zone of tall fescue adaptation. The intermediate PF estimates mean steer ADG for each treatment in future years and pastures at similar locations to those where the trials were conducted. 


\section{RESULTS AND DISCUSSION}

The detailed procedures and biological interpretation of the combined analysis have been published (Thompson et al., 1993) and therefore it is neither necessary nor appropriate to restate these details here. Nevertheless, some of this information will be repeated here to illustrate the possibilities of the combined analysis with linear mixed models.

Generalized least squares treatment means and their SE for the combined spring mixed model analysis varied with the treatment and the implied inference space (Table 1). The least squares means for the broad inference space epitomize the expected treatment performance in future years and for different pastures and locations within the eastern United States zone of tall fescue adaptation (Figure 1). The ranges in means observed in the individual trials at the several locations illustrate the wide diversity that existed within the combined data set.

The ADG of steers grazing LE and LECL pastures were consistently larger than those of steers grazing $\mathrm{HE}$ or HECL pastures. Mean ADG of steers grazing ME or MECL were intermediate between those of steers grazing LE and those grazing HE tall fescues, with and without clover.

The broad inference space SE were about 3 times larger than those for the narrow inference space because they represent variabilities corresponding to the entire population of years, locations, and blocks, of which those specifically observed in the combined datasets are random representatives. The SE for the narrow inference space are much smaller because they represent treatment variabilities for the fixed spectrum of years, locations, and blocks, when and where the data were collected. The intermediate inference space errors are between those of the broad and the narrow inference spaces. The intermediate inference space predictors incorporate the fixed effect of climate (years within locations) with the random effect of environmental variability (all other model effects).

The means, just like the SE, differ because of the numbers of observations and the inference space chosen. In both broad and intermediate inference spaces, the ranges among the tall fescue treatment means were less than for the narrow inference space. Thus, a prediction of differences among tall fescue treatments to an unknown location in future years is smaller, but with a larger SE, than a prediction of differences to a specific location with year effects equivalent to those obtained when these data were collected. The SE were larger for ME than for the other treatments primarily because of the smaller number of observations for ME.

The combined results substantiate the consistent findings of the discrete trials, reported elsewhere (Thompson et al., 1993). Combining information from similar trials to detect small, but real, differences was not necessarily imperative for these tall fescue treatments. Nonetheless, combining several trials provided more widely generalized estimates of steer ADG, the broad inference spaces, than did each independent 
investigation. These estimates are more pragmatic because the broad inference spaces incorporate the realized values of the random effects of years, pastures, locations, and all possible interactions into the SE of the mean ADG estimates (Stroup, 1989a).

Results from the combined analysis also provide a more coherent body of information than do results obtained from each discrete trial because treatment means were adjusted for the initial weight and grazing days/ha covariates. Treatment means were adjusted downwards for pastures with a greater number of grazing days than the mean grazing days, and for pastures stocked with steers having heavier initial animal weights than the initial weight means, a biologically rational adjustment; the reverse occurred when grazing days and initial weight were less than the means.

The combined analyses detected differences within the set of six tall fescue treatments (Table 2). Some of the differences estimable in the combined analysis could not be estimated within the individual trials because none of them included the full complement of six treatments.

Steers grazing LECL gained $130 \mathrm{~g} / \mathrm{d}$ more than did those grazing LE (Table 2). On the other hand, spring ADG by steers grazing HECL and HE were virtually identical (Table 1). This finding suggests that including clover in highly infested tall fescue stands may not always ameliorate fescue toxicosis during spring grazing. Mean spring ADG did not differ $(\mathrm{P}=.19$ ) for steers grazing LE and ME tall fescue (Table 2).

There were fewer treatment differences in summer than in spring; none of the five pre-planned contrasts was significant at the .05 level (Table 2). The generally small ADG by steers in summer renders the detection of differences resulting from $\mathrm{E}+$ infestation and inclusion of clover more difficult. Nevertheless, there were similarities between summer and spring treatment ADG means. The mean ADG by steers grazing ME was virtually identical to that by steers grazing LE during summer, but they gained $150 \mathrm{~g} / \mathrm{d}$ more than did those grazing $\mathrm{HE}$ tall fescue pastures. In contrast to the spring results, steers grazing LECL and LE had similar ADG in summer. This similarity was expected because the percentage of clover in tall fescue stands decreases usually to $\leq 10 \%$ in mid-summer due to inadequate soil moisture, resulting in slower clover growth and possibly preferential grazing of clover. Steers grazing LECL and MECL had similar summer ADG.

Mean ADG was less for the combined spring + summer data than was ADG in spring alone, but differences among treatments were maintained at about the same magnitude (Tables 1 and 2). The spring + summer analysis consisted of considerably fewer data, in Tennessee and northwestern Georgia only, than the spring analysis, with results from trials at several locations in seven states. Hence, similarity in treatment effects was not expected because the spring data set represented steer gains from a considerably larger number of locations-years than the spring + summer data set. 


\section{SUMMARY AND IMPLICATIONS}

We have demonstrated that independent trials can be combined successfully where different numbers of observations are available from different locations to estimate steer performance from a larger number of treatments over a greater spectrum of years, locations, and pastures, than when independent analyses are considered separately. Mixed models analysis permitted the expansion of the results to inference spaces that included not only the immediate vicinity of the research locations but also intervening spaces within the biological range studied. Some relationships were apparent which had not been detected in the individual trials, permitting estimates of such effects as the influence of clover presence on ADG at locations where clover had not been studied. The establishment of cooperative projects, using a subset of common treatments with identical protocols within the larger set of the treatments investigated in individual trials, should further increase the applicability of combined analyses, particularly in disciplines where research demands many resources and much time.

\section{LITERATURE CITED}

Bacon, C. W., and M. R. Siegel. 1988. Endophyte parasitism of tall fescue. J. Prod. Agric. 1:45.

Blouin, D. C., and A. M. Saxton. 1990. General linear mixed models - User's manual, Version 1.0. Dept. Exp. Stat. Tech. Rep. Ser. No. TR-89-001, Louisiana State Univ., Baton Rouge.

Fribourg, H. A., C. S. Hoveland, and K. D. Gwinn. 1991. Tall fescue and the fungal endophyte -- A review of current knowledge. Tennessee Farm \& Home Sci. 160:30.

Harville, D.A. 1985. Decomposition of prediction errors.. J. Amer. Stat. Assoc. $80: 132$.

Hedges, L. V., and I. Olkin. 1985. Statistical methods for meta-analysis. Academic Press, New York.

Henderson, C. R. 1975. Best linear unbiased estimation and prediction under a selection model. Biometrics 31:423.

Hoveland, C. S. 1993. Importance and economic significance of the Acremonium endophytes to performance of animals and grass plant. In S. S. Quisenberry and R. E. Joost (ed.) Acremonium/Grass Interactions. Agriculture, Ecosystems and Environment 44(1-4):3. Elsevier Science Pub., Amsterdam, The Netherlands.

McLean, R. A., W. L. Sanders, and W. W. Stroup. 1991. A unified approach to mixed linear models. Am. Statistician 45:54. 
Petersen, R. G., and H. L. Lucas. 1960. Experimental errors in grazing trials. In Proc. 8th Int. Grassl. Congr., p 747. July 11-21. Reading, U.K. Alden Press, Oxford.

Stroup, W. W. 1989a. Why mixed models? In Applications of mixed models in agriculture and related disciplines. South. Coop. Ser. Bull. 343. p 1. Louisiana Agric. Exp. Stn., Baton Rouge, LA.

Stroup, W. W. 1989b. Predictable functions and prediction space in the mixed model procedure. In Applications of mixed models in agriculture and related disciplines. South. Coop. Ser. Bull. 343. p. 38. Louisiana Agric. Exp. Stn., Baton Rouge, LA.

Stuedemann, J. A., and C. S. Hoveland. 1988. Fescue endophyte: history and impact on animal agriculture. J. Prod. Agric. 1:39.

Thompson, R. W., H. A. Fribourg, J. C. Waller, W. L. Sanders, J. H. Reynolds, J. M. Phillips, S. P. Schmidt, R. J. Crawford, V. G. Allen, D. B. Faulkner, C. S. Hoveland, J. P. Fontenot, R. J. Carlisle, and P. P. Hunter. 1993. Combined analysis of tall fescue steer grazing studies in the eastern United States. J. Anim. Sci. $71: 1940$. 
Table 1. Combined spring ADG (g/d) arithmetic and predicted mixed model means for stcers grazing tall fescue pastures infested at different levels with the Acremonium coenophialum endophyte.

\begin{tabular}{|c|c|c|c|c|c|c|c|c|c|c|c|c|}
\hline \multirow{3}{*}{$\begin{array}{l}\text { Tall fescue } \\
\text { treatment' }\end{array}$} & \multirow{3}{*}{$\begin{array}{l}\text { No. } \\
\text { of } \\
\text { obs. }\end{array}$} & \multirow{3}{*}{$\begin{array}{l}\text { Arith- } \\
\text { metic } \\
\text { mean }\end{array}$} & \multicolumn{6}{|c|}{ Predicted Means } & \multicolumn{4}{|c|}{ Means among individual locations } \\
\hline & & & $\begin{array}{l}\text { Narrow } \\
\text { inference }\end{array}$ & & $\begin{array}{l}\text { Inter- } \\
\text { mediate } \\
\text { inference }\end{array}$ & & $\begin{array}{l}\text { Broad } \\
\text { infer- } \\
\text { ence }\end{array}$ & & Maxi & & & \\
\hline & & & space & SE & space & SE & space & SE & mean & SE & mean & SE \\
\hline \multicolumn{13}{|l|}{ No Clover: } \\
\hline $\begin{array}{l}\text { Low E+ } \\
\text { (LE) }\end{array}$ & 98 & 932 & 914 & 20 & 904 & 36 & 841 & 55 & 768 & 169 & 1050 & 152 \\
\hline $\begin{array}{l}\text { Mod. E+ } \\
\text { (ME) }\end{array}$ & 13 & 829 & 825 & 47 & 816 & 69 & 757 & 76 & 694 & 123 & 771 & 180 \\
\hline $\begin{array}{l}\text { High E+ } \\
\text { (HE) }\end{array}$ & 66 & 550 & 511 & 25 & 614 & 37 & 633 & 54 & 380 & 130 & 1050 & 144 \\
\hline \multicolumn{13}{|l|}{ Will Clover: } \\
\hline $\begin{array}{l}\text { Low E+ } \\
\text { (LECL) }\end{array}$ & 50 & 983 & 1025 & 30 & 1018 & 47 & 972 & 62 & 1001 & 205 & 1056 & 152 \\
\hline $\begin{array}{l}\text { Mod. E+ } \\
\text { (MECL) }\end{array}$ & 32 & 921 & 864 & 27 & 860 & 48 & 822 & 67 & 820 & 92 & 995 & 109 \\
\hline $\begin{array}{l}\text { High Et } \\
\text { (IIECL) }\end{array}$ & 66 & 605 & 690 & 21 & 595 & 35 & 629 & 54 & 411 & 127 & 803 & 109 \\
\hline
\end{tabular}


Table 2. Linear contrasts for average daily gain (grams/day) by steers grazing tall fescue pastures at different levels of Acremonium coenophialum infestation, without or with clover (CL), during the spring and summer grazing seasons

\begin{tabular}{|c|c|c|c|c|c|c|}
\hline \multirow[b]{2}{*}{ Linear contrast } & \multicolumn{2}{|l|}{ Spring } & \multicolumn{2}{|l|}{ Summer } & \multicolumn{2}{|c|}{ Spring + summer } \\
\hline & $\begin{array}{l}\text { Predicted } \\
\text { difference }\end{array}$ & $S E^{1}$ & $\begin{array}{l}\text { Predicted } \\
\text { difference }\end{array}$ & $S E^{2}$ & $\begin{array}{l}\text { Predicted } \\
\text { difference }\end{array}$ & $S E^{2}$ \\
\hline Low Et vs. Moderate Et & 84 & $64^{\mathrm{NS}}$ & 17 & $74^{\mathrm{NS}}$ & 9 & $55^{\mathrm{NS}}$ \\
\hline Moderate E+ vs. High E+ & 124 & $66 *$ & 151 & $82 \dagger$ & 183 & $62 \star \star$ \\
\hline Low $E+C L$ vs. Mod. E+ CL & 150 & $68 *$ & 25 & $46^{\mathrm{NS}}$ & 112 & $34 * *$ \\
\hline Mod. $E+C L$ vs. High E+CL & 193 & $56 * *$ & 66 & $37 \dagger$ & 147 & $28 * *$ \\
\hline Low $\mathrm{E}+\mathrm{CL}$ VS. LOW E+ & 131 & $53 * *$ & 61 & $44^{\mathrm{NS}}$ & 134 & $34 * *$ \\
\hline
\end{tabular}

1 Standard errors of the means for the broad inference space of future grazing years and different pastures of similar E+ infestation levels and clover incidence within the United States adaptation zone of tall fescue (about $32^{\circ}$ to $41^{\circ} \mathrm{N}$ lat. and $75^{\circ}$ to $95^{\circ} \mathrm{W}$ long.).

2 Standard errors of a difference for the broad inference space of future grazing years and different pastures of similar Et infestation and clover incidence within Tennessee and northwestern Georgia.

Ns = Not significant, $\dagger=$ Significant at $\mathrm{P}=.10, *=$ significant at $\mathrm{P}=.05$, $* *=$ significant at $\mathrm{P}=.01$ 


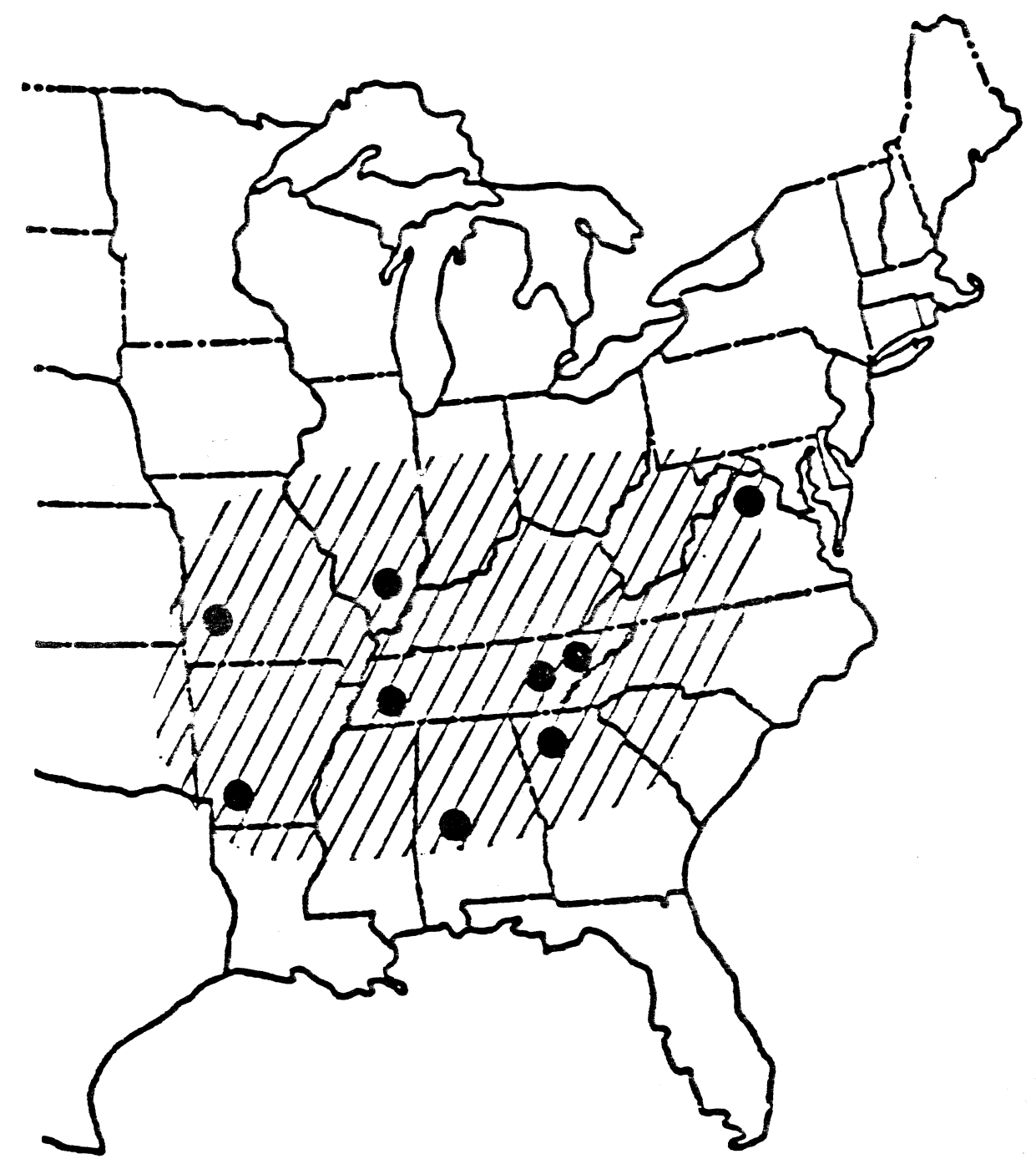

Figure 1. Map of the eastern United States with the approximate range of adaptation of tall fescue and the locations where the grazing investigations included in the combined analysis were conducted. 